\title{
DESENVOLVIMENTO PROFISSIONAL DE PROFESSORES NA CONSTRUÇÃO COLABORATIVA DE SEQUÊNCIAS DE ENSINO DE ESTATÍSTICA
}

\author{
PROFESSIONAL DEVELOPMENT OF TEACHERS IN THE \\ COLLABORATIVE CONSTRUCTION OF STATISTICS TEACHING \\ SEQUENCES
}

\author{
Eurivalda Santana \\ Universidade Estadual de Santa Cruz \\ eurivalda@uesc.br \\ Sandra Paula Almeida Nascimento \\ Universidade Estadual de Santa Cruz \\ sandrapaula1802@gmail.com \\ Maria Elizabete Souza Couto \\ Universidade Estadual de Santa Cruz \\ melizabetesc@gmail.com
}

\begin{abstract}
Resumo
Este artigo tem como objetivo analisar elementos para o desenvolvimento profissional de professores que ensinam conceitos estatísticos nos anos iniciais, ao desenvolverem sequências de ensino, construídas de forma colaborativa num projeto em parceria Universidade com Escola Pública. A investigação está fundamentada em pressupostos teóricos sobre desenvolvimento profissional de professores evidenciadas por Day, Nóvoa, Tardif, Marcelo Garcia e Ponte. Essa pesquisa de abordagem qualitativa, acompanhou os professores durante os encontros formativos, em serviço, quando o grupo planejava as sequências e socializava suas reflexões, bem como no desenvolvimento das sequências em sala de aula. Foram planejadas e desenvolvidas duas sequências de ensino seguindo as fases do Ciclo Investigativo - Problema, Planejamento, Dados, Análise e Conclusão (PPDAC), nas quais foram trabalhados os conceitos de moda, gráficos e tabelas de distribuição de frequência. Os dados foram coletados a partir das narrativas dos professores, por meio de observações diretas, entrevista e das gravações de áudio e vídeo dos encontros formativos, bem como material produzido pelos estudantes. Os resultados indicam que é possível oportunizar experiências de aprendizagens no que se refere à prática do professor com a implementação do Ciclo Investigativo, por meio do planejamento das sequências de ensino no grupo colaborativo, nos processos de reflexão na prática e sobre a prática realizada e ao renovar e ampliar o Conhecimento Específico do professor. Essas experiências de aprendizagem reverberam positivamente para o desenvolvimento profissional do professor que ensina matemática (conceitos estatísticos) nos anos iniciais.
\end{abstract}


Palavras-chave: Desenvolvimento Profissional Docente; Reflexão sobre a prática; Educação Estatística; Conhecimento Didático.

\begin{abstract}
This article aims to analyze elements for the professional development of teachers who teach statistical concepts in the early years, when developing teaching sequences, built collaboratively in a project in partnership between the University and the Public School. The investigation is based on theoretical assumptions about professional development of teachers evidenced by Day, Nóvoa, Tardif, Marcelo Garcia and Ponte. This research with a qualitative approach, followed the teachers during the formative meetings, in service, when the group planned the sequences and socialized their reflections, as well as in the development of the sequences in the classroom. Two teaching sequences were planned and developed following the phases of the Investigative Cycle - Problem, Planning, Data, Analysis and Conclusion (PPDAC), in which the concepts of mode, graphics and frequency distribution tables were worked. The data were collected from the teachers' narratives, through direct observations, interviews and audio and video recordings of the training meetings, as well as material produced by the students. The results indicate that it is possible to provide learning experiences with regard to the practice of the teacher with the implementation of the Investigative Cycle, through the planning of teaching sequences in the collaborative group, in the processes of reflection in practice and about the practice performed and the renew and expand the teacher's Specific Knowledge. These learning experiences reverberate positively for the professional development of the teacher who teaches mathematics (statistical concepts) in the early years.

Keywords: Teacher Professional Development; Reflection on practice; Statistical Education; Didactic Knowledge.
\end{abstract}

\title{
INTRODUÇÃO
}

Dentre os aspectos a serem considerados como pilares para a formação profissional do professor está a necessidade de repensar a profissão de docente, sobre a vertente da construção profissional dos professores, do posicionamento relativo à sua formação e ao seu desenvolvimento profissional. Partimos do princípio de que a sociedade tem passado por profundas modificações tecnológicas, sociais, culturais, econômicas e políticas. Em todas essas situações, o papel do professor precisa acompanhar tais movimentações.

Nesse caminhar, é preciso refletir e considerar que "o professor tem de ser chamado a desempenhar o papel de protagonista. Não é possível modificar a escola contra ele ou apesar dele" (PONTE, 1994, p. 1). Compreendemos que o professor é o ator principal de um sistema que, muitas vezes, o vê como único responsável pelas ações na escola e, também, como a solução para alcançarmos a aprendizagem e estimular o interesse dos estudantes. Para tanto, esse profissional necessita de um movimento formativo constante, podendo ser por meio de cursos de graduação, especialização, mestrado, doutorado, ou mesmo numa instância acadêmica mais breve, como palestras, seminários, participação em grupos colaborativos, em que o objetivo passa a ser, então, contribuir para a formação 
pessoal e profissional e, consequentemente, para o desenvolvimento profissional docente.

A ideia de desenvolvimento profissional do professor perpassa um processo em construção constante. E o desejo de manutenção de um processo educativo proveitoso e enriquecedor que não depende exclusivamente da vontade do professor. Esse processo necessita de articulações entre as instituições que compõem o sistema educacional. Dessa forma, as escolas não podem mudar sem o empenho dos professores; e eles não podem mudar sem uma transformação das instituições em que trabalham (NÓVOA, 1992).

Nesse sentido, o professor não se desenvolve sozinho, passivamente. Seu desenvolvimento profissional caracteriza-se por uma participação ativa na construção do seu próprio aprendizado. Essa construção pode ser individual ou coletiva, de forma colaborativa, na instituição que trabalha ou em outras, ao longo de sua carreira, mas fazendo com que o docente acompanhe as mudanças, reflita, reveja e renove seus conhecimentos na perspectiva de desenvolver boas práticas de ensino.

O professor, ao desempenhar papel essencial na construção do seu conhecimento, na ampliação de habilidades e competências, contribui a um processo de crescimento profissional ao articular os saberes adquiridos ou construídos em suas práticas docentes, melhorando não só resultados escolares dos estudantes, como reverberando na educação como um todo.

Nessa perspectiva é que objetivamos com o presente estudo analisar elementos para o desenvolvimento profissional de professores que ensinam conceitos estatísticos nos anos iniciais, ao desenvolverem sequências de ensino, construídas de forma colaborativa num projeto em parceria Universidade com Escola Pública.

\section{DESENVOLVIMENTO PROFISSIONAL DE PROFESSORES}

O conceito de desenvolvimento profissional é amplo e vai além da formação inicial e continuada. Por isso, buscamos nos estudos de Nóvoa (1992), Ponte (1994), Day (2001) e Marcelo Garcia $(1999,2009)$ identificar os elementos que influenciam e contribuem para o desenvolvimento profissional em uma construção colaborativa de professores dos anos iniciais.

O desenvolvimento profissional vai além da formação acadêmica, depende das suas vidas pessoais, profissionais, das políticas públicas e contextos escolares nos quais 
realizam suas atividades docentes. Se constitui num processo complexo, no qual "atribui uma importância crucial para a eficácia do ensino, à necessidade de manter e desenvolver o desejo da maioria dos professores em marcar a vida dos alunos" (DAY, 2001, p. 22).

Nesse sentido, o desenvolvimento profissional dá grande importância à combinação de processos formais e informais, assim como aos aspectos cognitivos e valoriza, também, os aspectos afetivos e relacionais do professor, não só os conhecimentos. Segundo Day (2001), boa parte das definições de desenvolvimento profissional defende os objetivos da aquisição de habilidades de ensino e de conhecimento relativos ao conteúdo ou a matéria a ensinar. No entanto, o autor acrescenta que a definição deve contemplar e ir além desses objetivos, definindo como o processo que,

[...] envolve todas as experiências espontâneas de aprendizagem e as atividades conscientemente planificadas, realizadas para benefício, direto ou indireto, do grupo ou da escola e que contribuem, através destes, para a qualidade da educação na sala de aula. É o processo através do qual os professores enquanto agente de mudança, reveem, renovam e ampliam, individualmente ou coletivamente, o seu compromisso com os propósitos morais de ensino, adquirem e desenvolvem, de forma crítica, juntamente com as crianças, jovens e colegas, o conhecimento, as destrezas e a inteligência emocional, essenciais para uma reflexão, planificação e prática profissional eficazes, em cada uma das suas vidas profissionais (DAY, 2001, p. 20-21).

Com essa definição, identificamos elementos como: as experiências de aprendizagem, adquirir e ampliar conhecimentos e as atividades planejadas, que acreditamos serem essenciais para compreender o desenvolvimento profissional. $\mathrm{O}$ professor além do papel ativo no seu desenvolvimento assume ser um agente de mudança, que pode rever, renovar e ampliar o compromisso com propósitos morais do ensino, buscando construir e desenvolver, de forma crítica, o conhecimento, competências essenciais de planejamento e escolhas didáticas, bem como habilidades para refletir e efetivar práticas de ensino eficazes.

Para Day (2001, p. 48) o ensino "é mais do que um ofício. É uma ciência educacional e uma arte pedagógica em que a prática, o conhecimento sobre a prática e os valores são tratados como problemas", pois o conhecimento explícito (conhecimento teórico da prática de ensino) rapidamente se torna implícito e imerso na própria prática. $\mathrm{Ou}$ seja, as ações do professor, como educador, são regidas por suposições tácitas, pelo que aprende no cotidiano do exercício da profissão, pelo conhecimento implícito que advém de um determinado contexto, fundamentando, assim, suas práticas e o planejamento de suas 
atividades.

O conhecimento do professor tem sido objeto de estudo de muitos teóricos e pesquisadores, pois as exigências em relação ao profissional de ensino vão além da transmissão do conhecimento. Esse profissional precisa incorporar em suas práticas as novas exigências impostas pelo sistema socioeconômico. Nesta direção, teóricos como Schön (1992), Zeichner (2008), Tardif (2014) e Shulman (1987, 2018) apresentaram importantes contribuições e teorizações sobre prática reflexiva, saber profissional contextualizado e o conhecimento profissional.

Com essa perspectiva, assumiremos como prática de ensino o ato de ensinar, as ações realizadas pelo professor com o objetivo de colocar em ação as teorias pedagógicas, com a finalidade de concretizar o processo de ensino em sala de aula, tendo em vista a aprendizagem dos alunos.

Segundo Shulman (1987), o professor deve ter uma base de conhecimento para o ensino e dominar o processo pelo qual os conhecimentos profissionais são construídos. Nesse sentido, analisar o que ocorre na aula pode proporcionar oportunidades para os professores aprofundarem os seus conhecimentos e potencializar possibilidades de reflexão sobre as eventuais mudanças nas suas práticas.

Neste contexto, a sala de aula pode se constituir como espaço dinâmico de ensino e mudança das práticas, envolto de complexidade, incitadas pelas mudanças contextuais, incluindo os avanços tecnológicos e as outras formas de relacionamento social, levando os professores a pensar sobre a sua prática de ensino. Desse modo, o desenvolvimento profissional pode vincular-se ao "[...] conjunto de processos e estratégias que facilitam a reflexão dos professores sobre a sua própria prática, que contribuem para que os professores gerem conhecimento prático, estratégico e sejam capazes de aprender com a sua experiência" (MARCELO GARCIA, 1999, p. 144).

Para isso, o professor, além de investigar suas práticas, precisa manter ininterrupta aprendizagem. E ser pesquisador enquanto mantêm um comportamento de contínua e permanente reflexão crítica no que diz respeito a seus propósitos e sua prática. É, pois, essencial que "reflectem na, sobre e acerca da acção empenham-se numa investigação com vista não só a uma melhor compreensão de si próprios enquanto professores, mas também tendo em vista a melhoria do seu ensino" (DAY, 2001, p. 47-48). 
Consideramos que a reflexão, também,

[...] significa que a produção de conhecimentos novos sobre ensino não é papel, exclusivo, das universidades e o reconhecimento de que os professores também têm teorias que podem contribuir para o desenvolvimento, para um conhecimento de base comum sobre boas práticas de ensino (ZEICHNER, 2008, p. 537).

Tendo esses olhares, é válido ressaltar que o ato de refletir não se restringe aos pesquisadores na busca de novos conhecimentos. O professor é reconhecido como produtor de conhecimentos tendo como base suas práticas. As atitudes baseadas na consciência analítica de seus próprios fazeres é que possibilitam esse docente tornar-se um professor reflexivo, como foi nomeado por Schön (1992).

Shulman (2018, p. 220) declara que a reflexão, no que tange ao professor, tem como propósito "rever, reconstruir, reconstituir e analisar criticamente o próprio desempenho e o da classe". O autor completa, afirmando, o propósito de "fundamentar as explicações em evidências dentro e fora da disciplina". Isso é o que faz um professor quando olha para o ensino e o aprendizado que acabaram de ocorrer e reconstrói, reencena ou recaptura os eventos, as emoções e as realizações. É por meio desse conjunto de processos que um profissional pode aprender com a experiência.

Segundo Schön (1992), o professor reflexivo se caracteriza da seguinte forma:

- Reflexão na ação: lida com as situações no momento em que elas surgem, são as tomadas de decisões por parte dos professores quando estão ativamente envolvidos no ensino, é uma atividade limitada ao contexto em que ocorre. É intuitiva. "A maior parte das aprendizagens na sala de aula envolvem a reflexãona-ação, uma forma de aprendizagem inconsciente, rotineira, intensa e orientada para a solução de problemas, o que limita o desenvolvimento profissional do professor" (DAY, 2001 p. 233). A reflexão pode ser retomada e compartilhada em outro momento envolvendo outras pessoas, passando a ser uma reflexão sobre a ação.

- Reflexão sobre a ação: acontece antes e depois da ação, é um processo mais elaborado e sistemático permitindo a análise, a reconstrução e a reformulação da prática no sentido de planejar o ensino e a aprendizagem em outras oportunidades, criando também a possibilidade de diálogos com outros agentes sobre as ações, como por exemplo ocorre nas Atividades Complementares (AC). 
Um professor que reflete na ação e a reflete sobre a ação produz novos saberes e novas estratégias para rever suas práticas, possibilitando mudanças no contexto em que se encontra, proporcionando, assim, um processo fundamental ao seu desenvolvimento profissional e ao de seus pares.

Os saberes produzidos pela reflexão são entendidos por Tardif (2011) como os saberes da formação profissional e, esses são constituídos pelos saberes que se referem aos conhecimentos científicos e didáticos para a prática pedagógica e são transmitidos pelas instituições de formação de professores; os saberes disciplinares correspondem aos vários campos do conhecimento, nesta pesquisa, refere-se ao conhecimento das ciências exatas, Matemática; os saberes curriculares estão relacionados à gestão dos conteúdos, os quais a instituição escolar apresenta como aqueles que serão estudados; e, os saberes da experiência são, especificamente, desenvolvidos no exercício das funções do professor e de suas práticas.

Assim como Tardif (2011), Veiga (2009, p. 35) argumenta que o trabalho docente "[...] não é algo que se aprende conhecendo de fora para dentro, mas uma atividade que se cumpre; como tal, no seio desse fazer, saberes que são mobilizados, construídos e reconstruídos". O saber profissional do professor não provém apenas da formação, da experiência, vem também da sua história de vida pessoal e das suas experiências espontâneas (TARDIF, 2002).

Nesta mesma perspectiva de construção de novos saberes, Shulman $(1987,2018)$, apresenta seis componentes que, segundo ele, constituem o conhecimento profissional dos professores:

- Conhecimento de conteúdo específico: conhecimento dos conteúdos das disciplinas escolares, ou conhecimento da matéria ou assunto. Conhecimento necessário para a docência e para que o professor possibilite condições a fim de que o estudante se aproprie deles.

- Conhecimento do currículo: refere-se ao conhecimento tanto do currículo específico da matéria ou assunto ou disciplina de determinada modalidade de ensino quanto da relação delas com a organização e a estruturação dos conhecimentos escolares. 
- Conhecimento pedagógico do conteúdo está relacionado a um novo tipo de conhecimento sobre o conteúdo que é construído pelo professor, diariamente, para ensinar o conteúdo e este é pensado, melhorado, refletido quando está relacionado a princípios, técnicas e a outros conhecimentos, por exemplo: do conteúdo específico, pedagógico geral, do currículo, dos alunos etc. Este é um conhecimento importante para e na docência, é da autoria do professor e é aprendido na trajetória profissional.

- Conhecimento dos estudantes e suas características: refere-se ao entrelaçamento de conhecimentos dos estudantes e da forma como aprendem.

- Conhecimento dos contextos educativos: contempla as particularidades sociais e culturais da comunidade em que a escola está inserida, passando pela administração e gestão da escola.

- Conhecimento dos objetivos, das metas e dos valores educacionais: relaciona-se com o conhecimento dos fins e propósitos educacionais e de seus fundamentos filosóficos e históricos.

Observamos que, além da experiência, os tipos de saberes e os conhecimentos específicos se fazem necessários para o bom desenvolvimento das práticas de ensino, visto que, os saberes, o ato de refletir os diversos tipos de conhecimento apresentados está entrelaçado na prática, no fazer docente.

Considerando que os conhecimentos da formação inicial não são, por si só, suficientes para preparar o futuro professor para ensinar, é imprescindível, que se faça presente a formação ao longo da carreira, com o caráter fundamental do autoconhecimento do professor, o desenvolvimento dos seus recursos e capacidades próprias, possibilitando ele próprio se tornar investigador das suas ações, bem como, ser o propulsor do seu desenvolvimento profissional.

\section{PROCESSO METODOLÓGICO}

O texto traz um recorte de um estudo desenvolvido ${ }^{1}$ com objetivo de analisar o

\footnotetext{
${ }^{1}$ NASCIMENTO, Sandra Paula Almeida. Desenvolvimento profissional de uma educadora Matemática em Educação Estatística. Dissertação de Mestrado em Educação Matemática. 135f., Ilhéus, BA: UESC, 2019.
} 
processo de formação com 12 professores dos anos iniciais em uma construção colaborativa sobre atividade de Educação Estatística, no que pode se reverberar para o desenvolvimento profissional. É uma pesquisa de abordagem qualitativa, pois "a fonte direta de dados é o ambiente natural, constituindo o investigador o instrumento principal", para a análise "os materiais registrados mecanicamente são revistos na sua totalidade pelo investigador, sendo que o entendimento que este tem deles o instrumento-chave de análise" (BOGDAN; BIKLEN, 2013, p. 47-48).

O universo do presente estudo constituiu-se em uma escola pública que atende estudantes dos anos iniciais do ensino fundamental. Todos os 12 professores e 04 coordenadores pedagógicos da escola participaram do processo formativo, assinaram o Termo de Consentimento Livre e Esclarecido (TCLE) e para preservar suas identidades atribuímos aos mesmos nomes fictícios, com as letras $\mathrm{C}$ e $\mathrm{P}$, sendo $\mathrm{C}$ para os coordenadores e P para professores. O projeto está registrado no Comitê de Ética em Pesquisa (CEP), com o protocolo número 859502117.6.1001.5526 e parecer consubstanciado número 2.593.004/2018.

Para a produção do material empírico, o que chamamos de coleta de dados, os procedimentos utilizados tiveram como base: as narrativas dos professores, observações diretas, entrevistas e gravações de áudio e vídeo nos encontros formativos que ocorreram no âmbito do grupo formado pelos professores da escola que ensinam matemática, coordenadores pedagógicos e pesquisadores da universidade.

Com o intuito de preservar a fidedignidade dos dados, utilizou-se dos seguintes recursos: diário de campo, vídeos, audiogravações e fichas de observação.

Este estudo foi produzido dentro de um processo formativo que teve sete encontros formativos, que buscou unir os objetivos individuais aos interesses do grupo, o que compreendemos como um método de trabalho colaborativo, em que todos se envolvem em busca de um interesse comum. O que para Roldão (2007, p. 27), mostra-se “essencialmente, como um processo de trabalho articulado e pensado em conjunto, que permite alcançar melhor os resultados visados, com base no enriquecimento trazido pela interação dinâmica de vários saberes específicos e de vários processos cognitivos".

Nesta perspectiva, o processo de construções colaborativas pode contribuir para unir professores da e na escola e, pesquisadores da universidade com o objetivo de diminuir 
as possíveis lacunas existentes entre a teoria e prática. Deste modo, as construções colaborativas podem favorecer o desenvolvimento profissional do professor, visto que as pessoas envolvidas no mesmo projeto compartilham suas experiências, seus conhecimentos e buscam encontrar métodos de ensino que favoreçam seu trabalho docente e que possibilitem uma aprendizagem eficiente, dos estudantes.

O grupo colaborativo foi organizado com a participação dos pesquisadores da Universidade e dos professores e coordenadores pedagógicos da escola com o objetivo de “criar nas escolas uma cultura de análise das práticas que são realizadas, a fim de possibilitar que os professores, auxiliados pelos professores da universidade, transformem suas ações e as práticas institucionais" (ZEICNHER, 1993, apud PIMENTA, 2006, p. 36), uma cultura de estudos sobre os conceitos as serem ensinados e uma cultura de planejamento coletivo com situações de ensino que estejam fundamentadas em uma prática investigativa.

Conforme descreve Pimenta (2006), para nós, um dos desafios da pesquisa colaborativa, também, foi conquistar e estabelecer vínculos de confiança, estudos e afetividade com os professores da e na escola. Uma construção contínua. Assim, a pesquisa foi organizada em momentos formativos com estudo, planejamento com os professores de acordo o ano escolar que lecionavam, socialização e reflexão da prática pedagógica, considerando que em todos os momentos a 'voz' do professor era o norteador de encaminhamentos, tomada de decisão e discussão da e sobre a prática pedagógica.

Nessa direção, a nossa pesquisa vem construindo essa cultura na escola, principalmente, com os professores que lecionam Matemática (objeto de estudo da pesquisa) tendo como ideia central

[...] a construção de práticas de trabalho a partir das culturas da escola e da universidade, que gere conhecimento para ambos e, principalmente, contribua para o desenvolvimento profissional de todos os envolvidos e para melhoria dos processos de ensino e aprendizagem da Matemática. (FERREIRA, 2003, p. 108)

Nesse sentido, recorremos aos estudos de Lopes (2003, p. 48) enfatizando que "o processo formativo se dá no movimento ensinar, aprender, ensinar, tornando nosso papel e postura, como investigadores, um resultado da concepção de Educação que reformulamos ao longo de nossa carreira de educadores" assim, a construção colaborativa pode contribuir, eficazmente, para o desenvolvimento do professor, e, por consequência, gerar impactos no 
desenvolvimento da aprendizagem dos professores e dos estudantes.

Neste sentido, o processo formativo foi embasado no modelo formativo RePARe (Reflexão-Planejamento-Ação-Reflexão) conforme Figura 1, elaborado por Magina, Santana, Santos e Merlini (2018) e adaptado ao contexto do projeto desta pesquisa.

A proposta propõe um movimento espiralar que começa com a reflexão teórica e que não termina com a reflexão empírica, mas gera um novo movimento da espiral RePARe (MAGINA et al, 2018). A partir dos resultados, retorna-se para um novo planejamento, começando a descrever uma nova espiral, tendo como base os resultados obtidos e, assim, traçando-se outros contextos.

Figura 1 - Modelo da espiral RePARe adaptado a este estudo

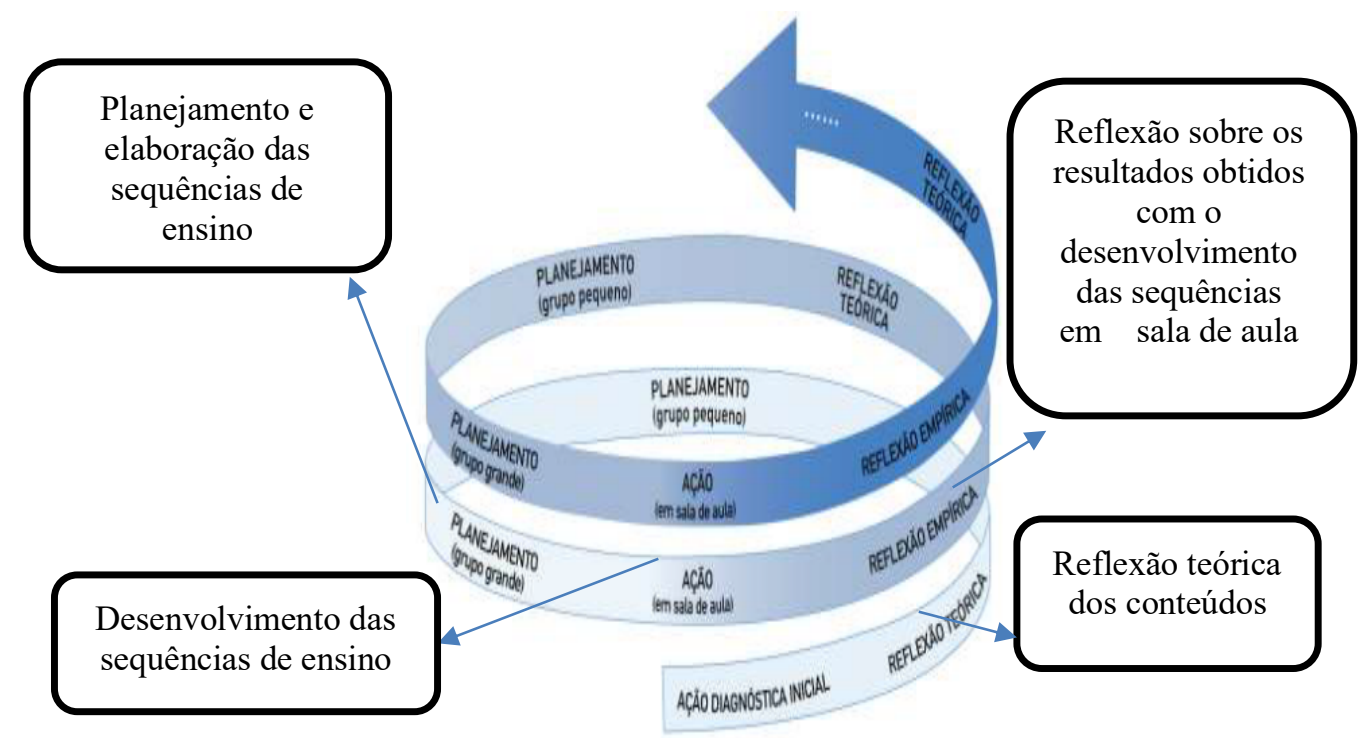

Fonte: Adaptado de Magina et al (2018).

Nesse modelo formativo se assume a reflexão como:

relacionada ao pensar e repensar as ações realizadas. São de dois tipos: teórica e empírica. REFLEXÃO TEÓRICA - quando a reflexão ocorre sobre os resultados da ação diagnóstica. Acontece no âmbito do grande grupo e é orquestrada pelo formador. Esta reflexão dialoga com os conteúdos contidos no instrumento diagnóstico, os quais serão trazidos para a formação gradativamente. Dessa forma, a reflexão teórica acontecerá ao longo de todo o processo formativo, visto que os instrumentos diagnóstico, com seus respectivos conteúdos, serão refletidos por partes. REFLEXÃO EMPÍRICA - quando a reflexão ocorre sobre a ação. Acontece inicialmente em pequenos grupos e, na sequência, no grande grupo. É nesse momento que os professores refletem com colegas sobre como ocorreu na ação realizada em sala de aula e o(s) efeito(s) observado(s) sobre a aprendizagem dos estudantes. (MAGINA et al, 2018, p. 248).

No caso deste estudo, as reflexões teóricas aconteceram nos momentos formativos com o estudo e discussão sobre o ciclo investigativo e os conteúdos de Estatística ensinados 
nos anos iniciais do ensino fundamental.

$E$ as reflexões empíricas, na formação quando estavam elaborando as sequências de ensino e em sala de aula no desenvolvimento das sequências. O modelo e o movimento da espiral RePARe, no processo formativo, ocorreu em datas previamente agendadas e de acordo com a disponibilidade da escola, sendo organizado e ministrado pelos pesquisadores tendo a participação ativa dos professores nas discussões e tomadas de decisão.

A reflexão aconteceu em vários momentos, principalmente, após o desenvolvimento das sequências em sala de aula, ao refletir a ação e sobre a ação (SCHÖN, 1992; DAY, 2001; ZEICHNER, 2008) com os colegas, coordenadores pedagógicos e pesquisadores. Essa oportunidade gerou uma situação em que a reflexão teórica e empírica se constituiu em ações de aprendizagens sobre a prática docente e os conteúdos de Estatística.

Para este artigo apresentamos e analisamos as reflexões dos coordenadores pedagógicos e dos professores no momento das discussões da sua prática sobre o desenvolvimento das sequências de ensino em sala de aula, nos encontros do processo formativo. As sequências estavam fundamentadas no ciclo investigativo (PPDAC), proposto por Wild e Pfannkuch (1999).

\section{O Ciclo Investigativo - PPDAC}

Nesta pesquisa, o objeto matemático envolve os conteúdos de Estatística, e as sequências, seguiram as cinco fases do ciclo investigativo. A escolha do PPDAC, justificase por ser esse um método que tem como objetivo trabalhar o pensamento científico e com conceitos estatísticos. Este ciclo conta com as seguintes etapas: construção do Problema (P), Planejamento (P), Dados (D), Análise (A) e Conclusão (C).

A seguir, apresentamos as fases do PPDAC (Figura 2), proposto por Wild e Pfannkuch (1999) com os elementos e procedimentos trabalhados na produção das sequências de ensino: 
Figura 2 - Fases do PPDAC e seus elementos

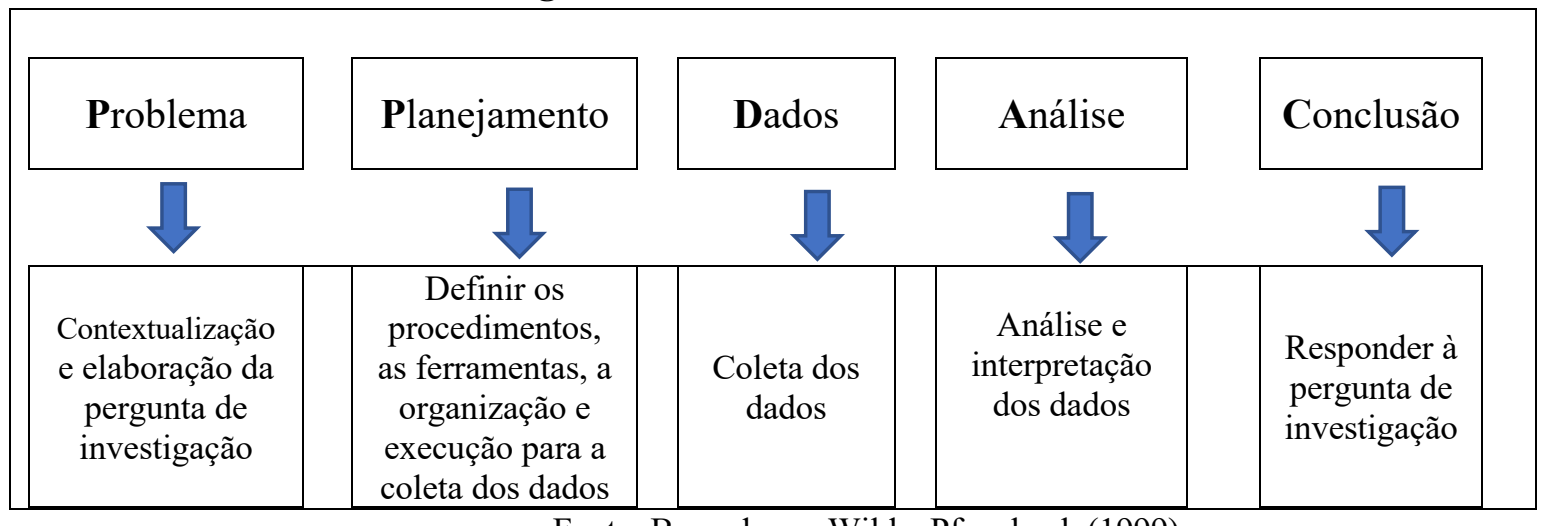

Fonte: Baseado em Wild e Pfannkuch (1999).

Na Figura 2 apresentamos as fases e os elementos para o desenvolvimento de uma sequência de ensino na perspectiva do ciclo investigativo. O PPDAC é um ciclo de investigação que não se resume apenas ao estudo e tratamento de dados. É uma possibilidade para estudo, coleta de dados, análise e reflexão sobre um determinado fenômeno, que se inicia com a compreensão do tema escolhido, bem como as relações sociais, conceituais, econômicas, afetivas que estão imbricadas entre os fatores que o condicionam. Em seguida, passa para a definição do problema de investigação e as demais fases: planejamento, coleta, organização, processamento e análise de dados. Com a análise pode-se gerar novas evidências e questões de investigação (WILD; PFANNKUCH, 1999).

O PPDAC pode ser pensado no contexto das metodologias ativas, considerando que o professor e o aluno são ativos, com vez e voz, para "estabelecer relações, fazer generalizações e sínteses para formar novos conceitos; e, finalmente, o conteúdo é ativo porque construído por meio da prática social dos homens, em condições históricas determinadas" (FACCI, 2011, p. 137). Nesse sentido, o ponto de partida para a aprendizagem é a discussão e reflexão da problematização, um momento para aprender a questionar a realidade, levantar hipóteses, coletar dados, analisá-los e socializar.

Os professores elaboraram sequências de ensino considerando as fases do PPDAC. Nesse contexto, vamos analisar as reflexões e como eles foram construindo novos conhecimentos da docência e do conteúdo de Estatística.

\section{ANÁLISE DOS RESULTADOS}

Analisaremos as reflexões realizadas nos encontros formativos sobre as elaborações 
e desenvolvimento das sequências de ensino, a partir das narrativas dos professores da escola por meio de um grupo colaborativo, com base na proposta do movimento espiral RePARe (MAGINA et al, 2018).

A reflexão teórica inicial, anterior a elaboração da primeira sequência, foi apoiada em um texto sobre os conceitos estatísticos, referentes: (i) as variáveis categóricas, (ii) o conceito de moda e média, (iii) construção de um banco de dados, (iv) tabela e, (v) gráfico. $\mathrm{O}$ objetivo era que os professores compreendessem os conceitos e, assim, elaborassem a sequência seguindo os passos do ciclo investigativo PPDAC. Após as discussões sobre o conteúdo os professores e uma coordenadora avaliaram o encontro se referindo ao conteúdo estatístico e fizeram os seguintes comentários:

C - Hera: Outro olhar sobre o trabalho em sala de aula.

P - Dóris: Um assunto complexo. Não lembrava o que era moda. Hoje lembrei.

C - Hera: Estudo, leitura e compreensão, ficou mais fácil.

P - Cifis: Os exemplos facilitaram.

C - Circe: Um processo para aprender.

Os professores demostraram que consideraram importante o estudo sobre os conceitos estatísticos e sobre o planejamento de uma sequência de ensino fundamentada no PPDAC, afirmando a dificuldade para a compreensão dos conceitos estatísticos e a coordenadora Hera ver a possibilidade de estabelecer outra compreensão para o trabalho a ser desenvolvido em sala de aula. Situação justificada por Circe quando diz "um processo para aprender" referindo-se a elementos conceituais e procedimentais a serem aprendidos no processo. Em seguida, o professor Dionísio ratifica, dizendo:

\section{P - Dionísio: O professor precisa de segurança da teoria para ajudar na prática, o envolvimento do aluno favorece a aprendizagem.}

Dionísio enfatiza a importância do professor ter domínio do conteúdo para concretizar o processo de ensino em sala de aula, o que Shulman (1987) classifica como conhecimento específico do conteúdo, bem como o conhecimento pedagógico do conteúdo. Dionísio declara que o domínio do professor favorece a aprendizagem do estudante, bem como a intersecção entre os dois conhecimentos: da matéria de ensino - estatística - e o conhecimento pedagógico - a sequência de ensino com o PPDAC. Nesta mesma linha de pensamento, Isis e Sofia dizem:

P - Isis: Fazer pesquisa com os alunos e de maneira interdisciplinar com outras disciplinas, o professor vai construindo o conhecimento com as crianças. Uma fundamentação teórica, explicação detalhada para a aprendizagem do professor e do aluno. 


\section{P - Sofia: Muitas vezes a gente trabalha com exemplo pronto. A experiência de vida, às vezes, é reproduzida em sala de aula e, muitas vezes, falta $o$ conceito. Agora, temos consciência da conexão do conteúdo através dessa formação.}

Isis compreende a proposta do PPDAC numa perspectiva de um trabalho interdisciplinar e a construção do conceito. Sofia, ao complementar as colocações de Isis, faz referência às práticas em uso de maneira geral, sem que o professor saiba o conceito que está trabalhando com o estudante. E, ainda, fez menção às experiências de vida que, em muitas situações, se constituem em práticas de ensino sem o conhecimento necessário dos conceitos. Sobre isso, Lopes (2008, p. 64) diz que "faz-se necessária uma combinação adequada entre o conhecimento sobre o conteúdo matemático a ser ensinado e o conhecimento pedagógico e didático de como ensiná-lo”, indicando como elemento central do conhecimento profissional do professor, o conhecimento pedagógico do conteúdo (SHULMAN, 1987). No entanto, só o conhecimento pedagógico para desenvolver o trabalho em sala de aula não é suficiente, sendo necessário estabelecer uma conexão entre esse conhecimento pedagógico dos estudantes e do conteúdo (SHULMAN, 1987) a ser ensinado, tornando-o compreensível aos estudantes.

Seguindo o movimento da espiral RePARe (MAGINA, et al 2018) o momento do planejamento (encontro seguinte), foi aberto por uma discussão a respeito dos conceitos. Quando interrogados pela pesquisadora acerca das dúvidas do conteúdo estudado, Sofia considerou gráficos de barras como ponto de partida e perguntou: “Quando as barras ficam juntas, ou ficam separadas?" Sofia (comunicação pessoal, 13 julho de 2018). A pesquisadora explicou a diferença entre gráfico de coluna, de barra e do histograma, discorreu sobre quando é recomendada a utilização de cada tipo de gráfico. Para exemplificar a resposta, a pesquisadora construiu um gráfico de barra, usando como tema o meio de locomoção que as crianças usam para ir até a escola, tendo como variáveis o sexo (masculino e feminino) e as seguintes categorias: andando, bicicleta, carro ou ônibus.

Após essas reflexões sobre o conteúdo de estatística, feitas em grupo, por ano escolar, os professores começaram a elaborar a primeira sequência com o tema "Água". Ao final a professora Isis disse:

\footnotetext{
P - Isis: Eu achei muito válido e importante esse aprendizado, com o pessoal da área de Matemática. Eu estou aprendendo muito. Aprendizagem muito grande com o pessoal da Matemática, são mais práticos.
} 
A narrativa enfatizou a importância da construção do conhecimento numa oportunidade maior para partilhar as experiências e conhecimento num ambiente de entreajuda, o que Day (2001, p. 232) classifica de "amizade crítica". Isso demonstrou que a construção do conhecimento no grupo colaborativo dinamizou o processo e fazendo com que o professor analise, estude, renove e amplie (individualmente ou com outras pessoas, sejam colegas, educadores ou investigadores) de forma crítica o conhecimento, as técnicas e habilidades que serão essenciais para uma prática profissional de qualidade.

No encontro que houve a socialização sobre o desenvolvimento da primeira sequência (reflexão empírica) discutiu-se o desenvolvimento da sequência na sala de aula. Tomando a palavra, a professora Isis disse:

\section{P - Isis: Trabalho significativo, trabalhou-se a problematização de forma significativa, a atividade direcionada pelo professor e a construção do gráfico foi coletiva.}

Dando continuidade, Sofia falou:

P - Sofia: A utilização do PPDAC fez com que a problematização fosse trabalhada em um ciclo. Foi significativo porque trouxe o contexto para a realidade do aluno. $\mathrm{O}$ trabalho foi realizado em seis aulas, sendo cinco com a contextualização e uma na sistematização dos conceitos estatísticos. Houve dificuldades de explicar aos alunos os conceitos estatísticos.

Podemos inferir que Isis e Sofia direcionaram a reflexão sobre suas práticas atribuindo novos sentidos ao trabalho desenvolvido. Evidenciaram que foi significativo, mesmo indicando dificuldades, haja vista "o conhecimento profissional do professor tem natureza transdisciplinar, complexa e interliga os componentes empíricos da didática”. (LOPES, 2008, p. 64). Para tanto, aos professores é indispensável o conhecimento sobre a matéria, ter domínio do conteúdo (SHULMAN, 1987), neste caso, o conteúdo de Estatística para os anos iniciais do ensino fundamental, bem como ser capaz de organizá-lo mentalmente, de forma a estabelecer inúmeras inter-relações, ou seja, relacionar conteúdo ao ensino e à aprendizagem, em um processo de interação com os alunos (LOPES, 2008).

A coordenadora pedagógica Gaia questiona:

C-Gaia: Há dificuldade com a linguagem e as atividades estatística, a construção da tabela e do gráfico. Como ensinar isso ao estudante?

E a coordenadora Bia completa:

C - Bia: Dificuldade em sistematizar os dados.

As dificuldades apresentadas fizeram referência a interação entre o conteúdo e a 
prática. Como a dinâmica foi construída fundamentada no ciclo investigativo - PPDAC, nas primeiras fases que foram a contextualização do problema e o planejamento não citaram dificuldades, mas, na construção do banco de dados, da tabela e dos gráficos, análise e conclusão que eram necessárias a sistematização dos conceitos, relataram dificuldades.

A partir dessa reflexão, podemos constatar que os professores aprenderam quando estavam envolvidos numa "reflexão colaborativa", termo usado por Rocha e Ponte (2009), para justificar que "a maioria da aprendizagem é promovida a partir da discussão de ideias" e que é por meio da partilha de suas experiências que os professores aprendem, uns com os outros, apropriando-se da teoria, ao criticar as suas concepções e as dos outros, aumentando os seus conhecimentos e discutindo novas estratégias de ensino e aprendizagem.

Neste encontro se encerrou um primeiro movimento da espiral RePARe. Ficou claro que a reflexão teórica e a reflexão empírica estão interligadas. Para refletir sobre o desenvolvimento da aula, como aconteceu a ação, também se fez necessário o conhecimento dos conteúdos estatísticas - o lugar da teoria.

$\mathrm{O}$ encontro seguinte se destinou ao planejamento da segunda sequência. Este foi dividido da seguinte forma: reflexões das ações desenvolvidas pelos professores; resoluções de questões do conteúdo até então estudado; e, a elaboração da segunda sequência.

Os professores iniciaram relatando o que fizeram no intervalo entre esse encontro e o anterior. Sofia relatou que retomou o conteúdo, trabalhou o instrumento de pesquisa, enfatizando que, desta vez, os estudantes participaram de todo o processo. Disse:

\section{P - Sofia: Senti mais segura em realizar a atividade e, as crianças, também estavam mais seguras em termos de conhecimento. Entretanto, senti necessidade de aprender mais sobre o conteúdo.}

Sofia relatou que estudou o conteúdo e se apropriou dos conceitos antes de retornar os trabalhos, para fazê-lo com mais segurança. Neste processo, incentivou os estudantes a também participarem do estudo, fazendo uma pesquisa e produzindo um texto sobre o conteúdo para socializar em sala de aula. Relatou, ainda, a surpresa advinda do envolvimento da turma, tendo sido bastante significativo todo esse processo, num fluxo de ir e vir. 
No segundo momento, para sistematizar os estudos sobre o conteúdo de estatística, foi entregue uma tarefa para os professores responderem, composta de um banco de dados e sete questões. Nela, os professores teriam que recorrer à construção de tabelas de dupla entrada e gráficos. Ao concluírem, precisariam socializar suas respostas e as possíveis dificuldades que tiveram. Percebemos, pelas expressões e falas, que os professores ficaram assustados, justificaram que era muito grande, que não iriam dar conta, fizeram alguns questionamentos, tais como:

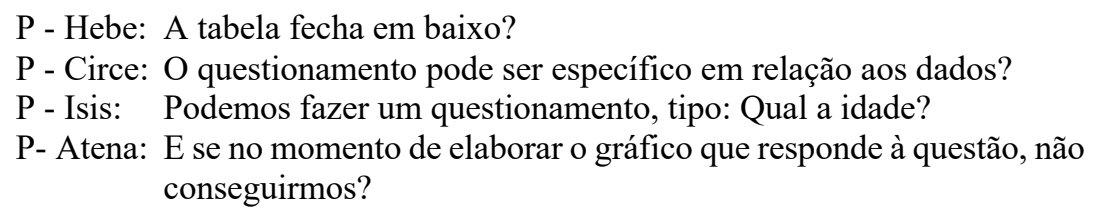

Os questionamentos que a maioria dos professores fizeram, permitiu identificar o que ainda não haviam se apropriado do conteúdo. Perguntados se tiveram dificuldades para resolver a tarefa, afirmaram que sim. Na sequência, Doris afirmou:

$$
\begin{aligned}
& \text { P - Doris: É difícil, desafiador, fiquei apavorada, mas é instigante, tem } \\
& \text { muita informação na tabela [banco de dados]. }
\end{aligned}
$$

Em seguida, após a explanação da pesquisadora para dirimir dúvidas, começou o terceiro momento: a elaboração da segunda sequência de ensino. Os professores se dividiram em pequenos grupos por ano escolar, o grupo de professores do $1^{\circ}$ e $2^{\circ}$ ano socializou a sequência elaborada com o tema higiene bucal. O grupo do $3^{\mathrm{o}}$ ano, apresentou a sequência delineada sobre o bullying e o grupo do $4^{\circ}$ e $5^{\circ}$ ano, com o tema alimentação saudável. No final do encontro, realizou-se uma nova avaliação.

Os professores afirmaram que tiveram dificuldades, e Sofia disse que foi "muito significativo, pois a minha dúvida também é do outro, tive dificuldade em detalhes" (Sofia). Iris complementou dizendo "quanto mais domino, melhor para trabalhar". $\mathrm{Na}$ conclusão desse encontro ficou elaborada a segunda sequência de ensino.

O encontro seguinte foi o último deste processo formativo e, nesse momento, foi feita a reflexão empírica. Começou com a socialização dos resultados da sequência de ensino realizada. Thor, ao descrever os procedimentos efetuados por ele, mencionou:

P - Thor: Primeiro contextualizei o tema com vídeos que tinham gráficos e tabelas. Os gráficos eram difíceis de entender [enfatizou], os estudantes tinham dificuldades, eles tinham defasagem na aprendizagem e não tinham condições de entender os gráficos. A maioria não acompanhou os conteúdos. 
Essa narrativa permite elucidar que ainda existiam muitas dificuldades que precisavam ser analisadas e estudadas, entre elas estava a escolha do material didático para aula, considerando que o uso de um vídeo durante a aula é para complementar, facilitar e apresentar outras possibilidades para o estudante aprender o conteúdo.

Sofia acrescentou que recorreu, junto com os estudantes, ao material que tinham produzido na sequência anterior para tirar algumas dúvidas, mas que, ainda assim, algumas dificuldades persistiam quanto aos conceitos estatísticos. Isis, por sua vez, concluiu que a sequência anterior contribuiu para a realização da segunda:
P- Isis: A construção não foi só das crianças, foi também da professora, que orientou as crianças que conduziram todo o processo, possibilitando refletir sobre as suas dificuldades.

Podemos inferir que, embora os professores relatassem suas dificuldades, mostravam-se dispostos, buscaram refletir. Sofia ilustrou bem isso, ao afirmar que não se tratava apenas de "um processo formativo, mas, sim, uma autoformação". É justamente o processo que Day (2001) chama de rever, renovar, no conceito de desenvolvimento profissional.

Na continuidade, foi solicitada uma breve avaliação dos encontros. As narrativas giraram em torno da necessidade de se continuar trabalhando conceitos, pois os assuntos precisavam ser consolidados, com mais profundidade. Os professores enfatizaram, ainda, que precisavam aperfeiçoar a questão das legendas, a interpretação, os conceitos, além de diversificar os tipos de gráficos. Chegaram à conclusão de que o desempenho dos estudantes estava saindo acima da média.

Quando cada professor relatou as aprendizagens, dificuldades, expectativas e avaliações do processo, as experiências vivenciadas por cada um, tornaram-se importantes para a sua própria reflexão e as dos demais professores, o que nos permitiu compreender que essas trocas de experiências, ligadas às atividades desenvolvidas, são propulsoras para as reflexões e aprendizagens dos professores envolvidos no processo formativo.

\section{CONSIDERAÇÕES FINAIS}

Ao fazermos a aproximação das narrativas produzidas pelos professores durante o processo formativo, identificamos que os estudos, planejamentos de sequências de ensino, 
as práticas de ensino e reflexões, produzem elementos que podem repercutir positivamente no desenvolvimento profissional de professores que ensinam Matemática, de maneira mais específica quando nos referirmos a prática de ensino com conceitos estatísticos.

As análises dos resultados indicam dois tipos de elementos principais que ocorreram como experiências espontâneas de aprendizagem dos professores: renovar e ampliar o conhecimento específico; rever e renovar a prática de ensino.

No que se refere ao conhecimento específico, os professores revelaram elementos como: aprender a aprender, aprendizagem com os conceitos de construção de tabelas e gráficos, determinar a moda e sistematizar dados estatísticos. Refletiram que estando diante da complexidade dos conceitos estatísticos o processo de estudo possibilitou renovar e ampliar o seu repertório de conhecimento sobre conceitos estatísticos, o que Shulman (1987) classifica como conhecimento de conteúdo específico. Sendo esses elementos observados quando revelavam que o processo formativo, o planejamento e a preparação para o desenvolvimento das sequências em sala de aula, auxiliavam a suprir lacunas de sua formação no que se refere a conceitos e definições específicas da Estatística. Suas dúvidas e dificuldades, em relação a conceitos estatísticos, foram sendo sanadas ao longo do processo formativo, com ações dentro do grupo colaborativo.

A reflexão sobre suas próprias práticas ocorreu associada ao domínio do conteúdo específico (construção do conhecimento estatístico), as reflexões feitas pelos professores confluíram com o seu próprio domínio do conteúdo e a condição que esse domínio dava para permitir ao estudante ser participante ativo de sua própria aprendizagem. Assim, os professores foram expressando outro olhar para concretizar o processo de ensino em sala de aula, tornar o PPDAC significativo, promover a prática interdisciplinar, interação com estudante, envolvimento e aprendizagem do estudante.

$\mathrm{O}$ ato de refletir na e sobre a prática (SCHÖN, 1992) foi motivado nos momentos de estudo do conteúdo estatístico e na construção de situações - sequência de ensino - para trabalhar com esses conteúdos em sala de aula. Percebemos, também, nas narrativas a busca pelo conhecimento, e essa busca é oriunda do ato da reflexão (SCHÖN, 1992).

O processo formativo constituiu-se de momentos de estudos, interação, construção de conhecimentos, aprendizagem e aproximação da teoria com a prática, em que os professores, por meio das narrativas e reflexões socializadas no grupo, compreendiam as 
situações que os incomodavam. O papel do grupo colaborativo e dos pesquisadores na construção e desenvolvimento das sequências de ensino se revelou essencial por ser o elo e o ponto de apoio dos professores, com relação as dificuldades em termos do conhecimento específico, permitindo um processo de formação continuada colaborativa no que diz respeito aos conceitos estatísticos para ensinar nos anos iniciais que, possivelmente, contribuiu para o desenvolvimento profissional, por meio das experiências de aprendizagem espontâneas (DAY, 2001).

Com as análises realizadas foi possível concluir que esses elementos indicam um processo de desenvolvimento profissional desses professores, parceiros nesse estudo.

\section{REFERÊNCIAS}

BOGDAN, R. C.; BIKLEN, S. K. Investigação qualitativa em educação. (M. J. Alvarez, S. B. dos Santos; T. M. Baptista, Trad.). Porto-Portugal: Porto Editora, (Obra original publicada em 1991), 2013.

DAY, C. Desenvolvimento Profissional de Professores, $1^{\text {a }}$ ed. Porto- Portugal: Ed. Porto Editora, 2001.

FACCI, M. G. D. A crítica às pedagogias do "aprender a aprender": a naturalização do desenvolvimento e a influência do construtivismo. In A. C. G. Marsiglia (Org.), Pedagogia Histórico-Crítica: 30 anos. São Paulo: Autores Associados, 2011.

FERREIRA. A. C. Metacognição e desenvolvimento profissional de professores de Matemática: Uma experiência de trabalho colaborativo. Tese de Doutorado. Universidade Estadual de Campinas-Faculdade de Educação. Campinas SP, 2003.

LOPES, C. E. O Conhecimento profissional dos professores e suas relações com Estatística e Probabilidade na Educação Infantil. Tese de Doutorado UNICAMP Campinas, SP, 2003.

LOPES, C. E. O ensino da estatística e da probabilidade na educação básica e a formação dos professores. Cad. Cedes, 28(74), 2008. p. 57-73. Disponível em: http://www.cedes.unicamp.br>.

NASCIMENTO, S. P. A. Desenvolvimento profissional de uma educadora Matemática em Educação Estatística. Dissertação de Mestrado em Educação Matemática. 135f., Ilhéus, BA: UESC, 2019.

MAGINA, S. M. P.; SANTANA, E. R. dos S.; SANTOS, A. dos; MERLINI, V. L. Espiral RePARe: um modelo metodológico de formação de professor centrado na sala de aula. REAMEC, 6(2), 2018. p. 01-22.

MARCELO GARCIA, C. Formação de professores para uma mudança educativa. Col. Ciências da Educação para o Século XXI. Porto: Porto Editora, 1999.

MARCELO GARCIA, C. Desenvolvimento profissional docente: passado e futuro. 
Revista de ciências da educação, 8 (1), 2009. p. 07-22.

PIMENTA, Selma Garrido. Pesquisa-ação crítico-colaborativa: construindo seu significado a partir de experiências na formação e na atuação docente. In: PIMENTA, Selma Garrido et al (Org.). Pesquisa em educação. Alternativas investigativas com objetos complexos. São Paulo: Loyola, 2006.

PONTE, J. P. da. Desenvolvimento Profissional do Professor de Matemática. Revista Educação e Matemática, 31(2), 1994. p. 09-20.

NÓVOA, A. Os professores e a sua formação (p. 13-33). Lisboa: Dom Quixote, 1992.

ROCHA, A.; PONTE, J. P. da. Aprender matemática investigando. Zetetike, 14(2), 2009, p. $29-54$.

ROLDÃO, M. C. N. Colaborar é preciso: questões de qualidade e eficácia no trabalho dos professores. Revista Noesis, 71(4), 2007. p. 24-29.

SCHÖN, D. A. Formar professores como profissionais reflexivos. In A. Nóvoa (Org.), Os professores e sua formação. 2. Ed. Lisboa: Dom Quixote, 1992. p. 77-91.

SHULMAN, L. S. Knowledge and teaching: foundations of the new reform. Harvard Educational Review, 57 (I), 1987. p. 01-22.

SHULMAN, L. S. Conhecimento e ensino: fundamentos para a nova reforma. Cadernos Cenpec. Nova série, v. 4, n. 2. 2018. Disponível em:

$<\underline{\text { http://cadernos.cenpec.org.br/cadernos/index.php/cadernos/article/view/293> }}$

TARDIF, M. Saberes docentes e formação profissional. Petrópolis: Vozes, 2002.

TARDIF, M.; LESSARD, C. O trabalho docente: Elementos para uma teoria da docência como profissão de interações humanas. 6.ed. Petrópolis, RJ: Vozes, 2011.

TARDIF, M. Saberes docentes e formação profissional. 17. ed. Petrópolis, RJ: Vozes, 2014.

VEIGA, I. P. A. A aventura de formar professores. Campinas, (Coleção Magistério: Formação e Trabalho Pedagógico). SP: Papirus, 2009.

ZEICHNER, K. Uma análise crítica sobre a "reflexão" como conceito estruturante na formação docente. Educ. Soc., Campinas, 29(103), 2008. p. 535-554. Disponível em: < http://www.scielo.br/pdf/es/v29n103/12.pdf $>$.

WILD, C. J.; PFANNKUCH, M. Statistical Thinking in Empirical Enquiry. International Statistical Review, 67(3), 1999. p. 223-265.

Submetido em 15 de novembro de 2020. Aprovado em 19 de fevereiro de 2021. 